\title{
Social Organization of Transgender Sex Workers
}

\author{
Anwaar Mohyuddin*, Muhammad Ali \\ Department of Anthropology, Quaid-i-Azam University, Islamabad, Pakistan \\ Email:*unwaar@gmail.com, alighous@gmail.com
}

Received September 16, 2013; revised October 18, 2013; accepted October 25, 2013

Copyright (c) 2013 Anwaar Mohyuddin, Muhammad Ali. This is an open access article distributed under the Creative Commons Attribution License, which permits unrestricted use, distribution, and reproduction in any medium, provided the original work is properly cited.

\begin{abstract}
This paper is an attempt to document life of male sex workers as transgender in Pakistan and to describe their cultural practices with reference to ritual performs on different occasion. Qualitative research methods combing in-depth interviews, FGDs, and observation were employed to gather information. An effort has been made to investigate the cultural life of the transgender and the pattern of their social interaction within the community as well as with the outsiders. Analysis based on thematic description of the themes generated after reviewing data. The research process revealed that males who were engaged in the sex industry have two types of sociological division: first, young and having male identity with potential to transform in transgender; while other transgender plays dual roles: a) within sex worker community as transgender women, b) male outside the transgender community. These males fulfill their socio-psychological and economic needs through entrance in the transgender community. Most of them consider themselves as having feminine soul and masculine body. The male engaging in sex work is a complex phenomenon with reference to their identity and performance of cultural rituals. An exploratory research study needs to be conducted to unfold the notion of dual identity which male sex workers have.
\end{abstract}

Keywords: Guru; Chela; Khusras; Kachay; Pakay; Yar; Garria; Power Structure

\section{Introduction}

Gender is not something we are born with, and not something we have, but something we do [1] and sex is a biological categorization based primarily on reproductive potential, whereas gender is the social elaboration of biological sex [2]. Around the world it is estimated that $2 \%-3 \%$ of biological males engage in cross-dressing [3]. Sex work has always been relevant to queer and transcommunities [4]. In most of the places around the world transgender is isolated from the society. As in India 85\% of the transgender is thrown out of homes to survive as sex worker and street dancer [5]. In contemporary usage, "transgender" has become an umbrella term that is used to describe a wide range of identities and experiences, including but not limited to: pre-operative, post- operative and non-operative transsexual people (who strongly identify with the gender opposite to their biological sex), male and female "cross-dressers" (sometimes referred to as “transvestites”, “drag queens”, or “drag kings”), and men and women, regardless of sexual orientation, whose appearance or characteristics are perceived to be gender

\footnotetext{
*Corresponding author.
}

atypical [6]. According to epidemiological category of biological male who sell sex, there are three sociologically different sexual identities: khusras (transgender), khotkis (feminized males) and banthas (mainstream male identity). Both khusras and khotkis are organized in strong social structures based on a shared identity [7]. However, to avoid imposing a "false clarity" on categorization of identity and assumed behaviour, it is necessary to go beyond verbal accounts to document the fluidity of everyday reality [7]. This would widen spectrum for the intervention to address issues and challenges which are faced by the transgender sex worker.

Transgender is one of the deprived groups of the society which are neglected in the social sphere. They are faced with situation of isolation stigma and hatred due to their identity crisis and the roles they are playing which push them to join the sex work profession. Most of the researchers have studied transgender with reference to the HIV/AIDS. However, very few of the researchers had focused their attention on the lives of transgender and their culture. So, this research study will share cultural life of the transgender and the community which they have created in already existing world. 


\section{Methodology}

This research study is based on the descriptive research design. This research design was adapted to get rich descriptive details about the culture of the transgender and other associated phenomena as this design could help us to know what, how and why the things are happening. We knew target population and were interested to capture their life in their community. So, descriptive research design was chosen to get the cultural insight. Qualitative research methodology was used for this study which mainly included in-depth interviews, focus group discussions and observation. With the use of qualitative methods it was possible to collect empirical data regarding their individual as well as their group lives. A sample of 30 sex workers aging between 15 - 45 years was selected through snow ball sampling technique. This sample included 20 male sex worker having transgender identity were interviewed along with 8 male sex worker have not transgender identity and 2 Gurus. In-depth interviews were conducted with all of them. For this research data was collected during September to December 2012 at Maripur Karachi Truck-Ada (truck stand) and residential places of the sex workers in Machor Colony and Agra Taj.

\section{Objectives}

1) To find out the way they (transgender) are in their social life.

2) To know the rituals, custom, norms perform by the transgender in their community.

3) To know transgender lives as sex worker.

\section{Demographic Profile}

As mentioned earlier 30 TGSW (transgender sex workers) aging between 15 - 45 years were selected as sample for this research. Majority among them were between 15 24 years. They belonged to different part of the Pakistan however; majority of them came from Punjab (Hyderabad, Sialkot, Bahwalpur, Faisalabad and Sahiwal). From their appearance and style they looked like khusras (the third-gender), but, most of them were transgender. Here by saying transgender we mean that they had changed their gender identity and were portraying themselves as female. While, by mean of biological division they were male. Along with these transgender other major group in this profession belonged to the Khusra community. By using word Khusra we mean those people who neither males nor the females. Some of the male were also working as sex worker and living with the transgender but they had dual role. When they were with transgender they had their feminine names and adopted conversation style like females. They performed and acted like transgender. However, on the other hand they had their wives and children and used to visit them back to their native area. Usually these types of sex workers were coming to the truck-stand as massager but not providing massage services to their clients, actually they were performing as sex workers. Hijras (the third-gender) of 40 years and above were working as pimp as well. Following is the sample profile (see Table 1).

\section{Results and Discussion}

The people in every society have different ranks as high and low. People in different societies are distributed in groups on the basis of this status called stratification. This stratification may be on the basis of occupations, caste, and education source of income, prestige and political power. The people attain these sources and get into a class. In this way the whole society is divided into a few classes, generally high, middle, lower middle and lower. Stratification among TGWS was also found but based on different factors. The first two are based on the age and the next two are based on the biological status and role. Their categories are as under.

- Kachay (young): Those who were less than 18 year of age or look younger like a child.

- Pakkay (mature): Those who were above age of 18 years.

Some other characteristics of stratification were also prevailing among them which are as under:

- Khusra: These were less in number but had prominent position among sex worker community. Most of the gurus (leaders) among sex worker community were "Khusras".

- Pimp: These were also less in number. Their role was to protect the sex workers and arrange customers for them. They worked as agents as well as the sex worker. Sometimes they transported sex worker from one place to other and took their share of money as booking or transport charges.

\subsection{Young Sex Workers (Kachay)}

These were the youngest group among TGWS and were found very less in number. Mostly they did not have any skills other then earn their livelihood through sex work

Table 1. Sample Profile.

\begin{tabular}{cccc}
\hline Sr & Age & Occupation & Frequency \\
\hline 1 & $15-18$ & & 6 \\
2 & $19-24$ & & 8 \\
3 & $25-29$ & Sex worker, Pimp, Massager, & 5 \\
4 & $30-34$ & & 5 \\
5 & $35-40$ & & 3 \\
6 & $41-45$ & Total & 3 \\
\hline
\end{tabular}

(Source: Socio-economic survey). 
profession. Mostly they lived with one or two elder partners, but not in big groups. They were totally under control of their partner and followed their direction in every walk of their life. Main reason behind this partnership was the protection for the younger because they were less confident and were finding it difficult to face the social surroundings. These young workers who lived with their partners were called as kachay and the people normally referred as, "un ki pakki nhi howi abhi tak" (they are not mature sex worker). One respondent said that "un ki abhi tak kachi hay" (they are immature sex worker). It means that they had opted sex as their profession but not working openly because they could not face police. They could not find their clients even. Their elder partners arranged clients for them who stayed in contact with them for a longer time. They did not change them frequently.

\subsection{Power Structure among Young Sex Worker (Kachay)}

Young transgender-sex workers, who were commonly known as kachay, were earning more money as compared to their elder colleagues. They had higher demand among the clients however; to approach them was difficult. They had fewer but permanent and regular clients who invested more on them. Their elder partner mostly worked as pimp for them and kept all the money with them. They just gave them pocket money. Some of the young sex workers became popular among clients due to their beauty and smartness, than elder partner became extra caring for them fulfilling most of their demands. When those youngsters started earning more and became popular they started demanding more power and autonomy with reference to their mobility, development of friendship and extra share of income. However, the elder partners exercised all the means and ways to control them. Ultimately those young sex workers became independent.

\subsection{Mature/Elder Sex Worker (Packay)}

The transgender sex workers aging 18 years and above are called as pakay. They mostly earn their livelihood through sex trade. However, life history of some of the workers indicated that in the past they were earning their livelihood through other occupations as well. In their appearance, some of them (packay) had dominant masculine characteristics with male identity and the others had feminine characteristics in their personality. Most of the transgender in this profession belonged to this category. They lived in shape of groups with one of them as their leader known as "guru". Some of the groups included khusras among them as well and those groups had a better reputation and respect. In majority of the cases guru are selected from the khusra community. However, notion of packa was not associated with the khusras. This term specifically referred to the adult transgender sex workers only. They were difference from kachay sex workers in different regards. They were not hiding themselves like the youngsters. They were known to the public living in their surroundings. They often visited public places in search of the clients as well. This openness basically was the demarcation between kacha and packa workers. One of the respondents (23 year old-sex worker) reported that "jin ki pakki ho jati hay wo hei kholay aam public mian a ker appna dhanda kerty hain or yeh tab hei hoti hay jab tajrba hota hay" (those who work openly know as mature, this happened when they acquire enough experience in sex industry).

\subsection{Power Structure among Packay}

As discussed earlier mostly adult workers (packay) lived in groups and their groups were controlled by the gurus. The place where they lived was known as dera. The group size varied from 3 - 6 members majority of which were transgender and sometime one or two khusras as well. They lived under defined rule and regulation of their guru who was considered as head of the family and had a significant influence on their lives. Guru also got some share from their income. He was looking after and taking care of all group activities. He was controlling the visits of the guest/clients as well. Mostly the sex workers sought his permission before inviting their clients or guests. One of the sex workers Dilshad (21 year of age) gave us an appointment but later refused because his guru did not allow him to bring us at their dera. He said, "Guru ji kehty hain kissi ko bahir say lanay ki zaroorat nhi hay" (guru says that you do not need to bring outside here). Researchers further inquired about the reasons why guru refused. He said, "Guru jo kehty hain theak kehty hain, guru tasali kay bagir kissi ko anay nhi detay" (what so ever guru says is right, without clarification guru do not allow out sider).

Guru was also responsible for the arrangements of the various rituals performed in their community. Gurus having performed more rituals and at larger scale were considered as big gurus. They had better reputation and respect in the community. Time of the rituals, participation, dress patterns and places were always finalized by the guru. Researchers could not attend any rituals because a long time was needed to earn their confidence and permission to attend the rituals. Even the members were not allowed to discuss place and time of any ritual which they called Jalsa. One of the respondents said, "Hum ko ijazat nhi hoti kay appni community say abhir kay logo ko Jalsay ki jaga ka batain" (We are not allowed to inform outsiders about the place of festival). 


\subsection{Yar Making Ritual (Marriage)}

One of the rituals performed among transgender was Yar Making Ritual. This ritual was similar to a marriage ceremony. Marriage is considered as union of two opposite sex people with socially legitimate sexual relationship. However, among transgender community Yar Making Ritual is performed between two people of same sex but different gender. The concept of yar among transgender sex workers vary from person to person. One of the respondents (18-year-old sex worker) stated, "Yar wo hota hay jo zada tar sath rehy or us say sab say zada pyar keray" (Yar is the person who lives with sex worker and loves him more than anybody). Another 24 year old-sex worker said, "Jo hum ko sab say zada pyar keray or hamari zaroorto ko pora keray wo Yar hota hay" (Yar is the person who loves us more than anybody and fulfills our needs).

Initially yar appears in the life of sex worker as client. Ultimately relations of intimacy, affectation, closeness brings both the parties (sex worker and client) close to each other. They start living together and stay with each other for most of the times. Sex worker community starts recognizing them as a couple having close relationship. In this regard one of the respondents a 33 year old-sex worker said, "Yar to wo hota hay jo har waqat sath ho or logo ko pata ho" (Yar is the person most often stays with the sex worker and people know about their relationship). Yar starts exercising his authority and control over the sex worker. He becomes his sole client and never likes to share his passive partner with any other. He never allows his to entertain the other clients. He solely bears his expenditures. Than sex worker demands his yar to perform Yar Making Ritual front of his community. Sometimes yar agrees to perform ritual and sometimes denies. One of the respondents a 23 year old-sex worker stated, "Yar to har koi bana chata hay magar yar banay ka hosla wo hei kerta hay jo sacha hota hay" (everybody wants to be a yar but very few of them dare to perform ritual jalsa).

As already discussed all the rituals performed among transgender sex workers were known as jalsa and controlled by guru. Main purpose of these rituals was just to arrange for community gathering. Yar Making Rituals were also controlled by the guru. However, the expenditures were mostly borne by the yar. These expenditures were directly associated with love and closeness among the worker and yar. If yar was truly in love with his partner (commonly known as garria) than he spent more. One respondent (37 year old guru) said, “jeetna zada yar pyar kerta ho ga woo otna zada khurcha keray ga” (the yar who loves more spends more). Another respondent (42 year old guru) stated, "Yeh yar ki zamadari hoti hay kay wo hamaray guru ki izat keray or un ko tohfa day" (this is yar's responsibility to respect guru and present him gifts).

Guru used to invite the community member for jalsa. However, before the invitation he consulted his chela (disciple of guru, a sex worker) to know about the amount of money given by the yar for the jalsa because lunch or dinner which is known as valima had to be served to all invitees. So number of the guests had to be in accordance with the money available. Yar presented gifts to the guru and sex worker at the occasion of Yar Making Rituals. He also presented ladies clothing to the yar for the occasion. Sex worker dressed up like a bride and used cosmetics also. If garria did not wear ladies dress, at least he had to put dupata (scarf) on his head. Among sex worker community all these kind of preparation enhanced the prestige of sex worker as well as his guru. A 26 year old-sex worker pointed out, “os din ka maza hei koch or hota hay jeetna acha jalsa hota hay otna hei hum khoob tyari kertay hain" (day of jalsa brings a lot of entertainment and our preparation is also linked with it. If the jalsa is bigger we prepare ourselves better).

The ritual completed after exchange of rings in the fingers of garria and yar. All the guests cheered, presented gifts to sex worker and yar. After performing Yar Making Ritual, garria was treated as wife of yar. While, in some cases sex workers fall in love with some specific client and started providing him services free of cost. Unconditionally and without any ritual they started living together. Garria bore all the expenditure of his yar and only demanded love, care and affectation from him. He always remained prepared for any type of sacrifice for his yar and in return he demanded faithfulness. He developed hatred and jealousy when his yar made sexual relation with other sex worker or when he did not give attention to him. Once a sex worker tried to kill his yar because, he was not paying full attention to him. Another 22 year old sex worker said, "agar yar tmara na ho to us ko kissi or ka bhe nhi hona chay". (If yar did not belong to you then he would not have relation with the others as well).

\subsection{Guru Making Ritual}

Guru was the most important person of sex worker community. Most of the gurus attained this status on the basis of their age, experience as sex worker and their relations with the community members. All of the gurus in this community were above 35 year of age and some of them had primary level education also. Two of them were skilled laborers who later switched over as sex workers. Two of them also had families in their native villages. Initially they started their carrier as male sex worker but later shifted their identity as transgender. They had multifaceted manifestation of gender identity. On one hand they were fathers, brothers, and sons, while on the other hand 
they were transgender with feminine name wearing ladies cloth and behaved like females.

Chela (sex worker) is the person who gave identity to other sex worker as a guru through acceptance of his experience and adoption as a leader who could support him. A 32 year old sex worker said, "Guru hay to hum hain" (our existence is because of guru). Another one said, "Guru to hamari ankhain hota hay" (guru is our eyes). Third respondent said, "Guru ki zindagi hei zamany dhekty howay guzarti hay jo wo janta hay main nhi janta (guru is experienced and he knows those things which we do not).

For this purpose chela organized a ceremony which was known as "Jalsa". In this ceremony chela and guru invited all other community member and performed a ritual. In this ritual guru made a whole in the ear of the chela. After performing this ritual and making whole in the ear they became guru and chela. Guru enjoyed the status of father/mother for his chela. During these ritual guests and the chela presented gifts to the guru and sometime guru also presented gifts to the chela as well. The value of the gift was determined by its price and preciousness. Presenting precious gift to guru enhanced his prestige and became a symbol of strong relationship between each other. A 29 year old respondent said, "Jeetna jalsa acha ho ga otni hei humari izat ho gi" (Julsa determine our respect).

\section{Conclusions}

Formation of transgender community is the coping strategy against the isolation and stigma. Most of the transgender had multifaceted manifestation of sexual identity. They were performing dual roles in their social and sexual life. When they had status of husbands and fathers they had identity of transgender as well. Most of them preferred to be "transgender women". It might be the reason that they were male and had feminine orientations in their self. They lived in groups and were controlled by the guru. Younger sex workers who even didn't have a complete identity as transgender used to live with one partner who actually controlled his business. However, as time went by, when he acquired his identity and started earning money then he joined the community of the transgender.

In addition, various rituals were performed by the transgender sex worker community. All of these rituals were created on the pattern of societal rituals. History of these rituals was not known, while its functional utility was visible. These rituals transformed their psychological condition through practical behavior. Through birth ritual transgender sex workers fulfill their psychological needs. Physically they were born as males but psychologically they wanted to be female. However, in their native community they were not allowed to be trans-women or they did not have courage to do so. Therefore, through marriage ritual they fulfilled their psychological need by playing bridal role. Furthermore, they faced stigma, hatred and aggression. So by performing this role they fulfilled their desire to have a person who loves them without discrimination on the basis of their identity.

Guru Making Ritual provided guider, protector and ah father to the transgender. He taught his chela about the profession and introduced him into the community. Being chela of Guru, sex workers acquired recognition and social prestige among their community. Moreover, economic as well as social utility was highly associated with all rituals. Sex worker community maintained power structure which performed various functions and fulfilled their social, moral, economic and psychological needs to sustain rigid behavior against their identity as sex worker.

\section{REFERENCES}

[1] C. West and D. H. Zimmerman, "Doing Gender," Gender and Society, Vol. 1, No. 2, 1987, pp. 125-151.

[2] P. Eckert and G. S. McConnell, "Language and Gender," Cambridge University Press, Cambridge, 2003. http://dx.doi.org/10.1017/CBO9780511791147

[3] B. Reed, et al., "Gender Variance in the UK: Prevalence, Incidence, Growth and Geographic Distribution,” Gender Identity Research and Education Society, 2009.

[4] P. S. Savati, "Sex Work and Queer Politics in Three Acts," 2013.

http://sfonline.barnard.edu/a-new-queer-agenda/sex-work -and-queer-politics-in-three-acts/

[5] http://www.dellchallenge.org/projects/transgender-astitv

[6] United Nation Development Programme, "Hijras/Transgender in India: HIV, Human Rights and Social Exclusion," 2013.

http://www.undp.org/content/india/en/home/knowledge-a nd-solutions/voices-of-the-marginalized/hijras_transgend erinindiahivhumanrightsandsocialexclusion/

[7] M. Collumbien, A. Qureshi, R. K. Verma and Naveedi-Rahat, "Reaching Male and Transgender Sex Worker Communities in Pakistan: Addressing Public and Private Identities," Presented at XVII International AIDS Conference, 3-8 August 2009, Mexico City, pp. 1. 